\title{
The problem of moral choice in early adulthood
}

\author{
Albina Gilyano $^{1 *}$, Dina Kazantseva ${ }^{2}$, and Irina Sokolovskaya $^{3}$ \\ ${ }^{1}$ Russian State Agrarian University - Moscow Timiryazev Agricultural Academy, 127550, \\ Timiryazevskaya Ul st., 49, Moscow, Russia \\ ${ }^{2}$ Southern Federal University, 344006, Bolshaya Sadovaya st., 105/42, Rostov-on-Don, Russia \\ ${ }^{3}$ Russian State Social University 129226, Wilhelm Pik str., 4, p. 1, Moscow, Russia
}

\begin{abstract}
In modern Russia, as a result of the moral degradation of society, the problem of moral choice of the individual became acute. In the implementation of life plans, the individual has a divergence of moral attitudes that exist in the sphere of unconsciousness, consciousness, and their manifestation in behavior. The period of early adulthood, 17-25 years, is characterized by the self-organization dynamics of internal factors that determine the main results of the period under the specific influence of the social environment, all these influences the choice of profession, the creation of a family, the development of the emotional sphere. In this regard, there is a need to study the peculiarities and dynamics of moral choice in the period of early adulthood in modern Russia. The methods of the research are theoretical analysis and generalization, questionnaires, participant observation, survey, methods of qualitative data analysis, and statistical data manipulation. The researches were carried out in 2007, 2010, and 2019 in Penza. The sample number was 244 people, 110 people, 101 male and female people aged 17-22. The research works have shown that the increase in the crisis in society, from 2007 to 2019 , negatively influenced the manifestation of high principles, moral qualities, the respect of moral traditions, the process of the achievement of the goal, and the confidence in the implementation of life plans. However, it was the crisis that made it possible to choose in favor of psycho-protective traditional foundations, specifically moral ideals, and values.
\end{abstract}

\section{Introduction}

The problem of moral choice during early adulthood, which exists in modern Russian society, is due to the moral degradation of the society and the need to implement a set of measures to overcome this state. The discrepancy of moral attitudes in the spheres of unconsciousness, consciousness, and behavior is explained by the individual's choice, this choice either generates moral behavior or blocks the desire for love, kindness, responsiveness, generosity, etc.

Moral education does not guarantee moral choice in practice. Moral realization is provided by the individual's moral qualities, the sufficient development of which allows

* Corresponding author: iren3d@mail.ru 
following the moral standards throughout life. The lack of them or small development facilitates the abandonment of moral behavior, that there is not much to gain from it in terms of comfort, self-interest, profit.

According to J. E. Birren`s classification of age-related periods of development, the period of early adulthood or youth covers the individual's life 17-25 years old. Each period is characterized, according to P. Baltes, by an internal dynamic of acquisition and loss, the capacity for both adaptation and acquisition, and loss and decline. Explaining the peculiarities of human development, J.G. Miller emphasizes that people are part of complex systems, social and physical environments.

In reality, a person grows and adapts to the social environment throughout his/her life. The developmental stability is achieved by the choice of each person as self-organizing, due to internal factors, without specific external influence, system.

The choice preference of moral qualities ensures the human system capability, dynamic stability, and developmental stability.

The peculiarity of the early adulthood period is the direction of development of life determination, which reveals itself in the choice of profession and the first professional achievements, the start of the family and responsibility for the procreation and the childrearing practices, the development of the emotional sphere and the achievement of emotional bond, the formation of a certain moral attitude to life, society, one's family.

The number of problems is solved in each of the following spheres professional, family, emotional. So if we take the emotional sphere, it is during this period that emotional bond is achieved as the basis of love, and identity; when one starts a family, a complex of emotions of parental attitude, love, spiritual affinity develops; professionally - professional personal qualities, organizational abilities, etc.

The period of early adulthood was described by E. Erickson, who highlighted the main result of this period, namely intimacy and emotional bond, the ability to establish a close relationship with warmth, understanding, trust; P.G. Heymans, who noted the need to show the ability to perform actions on your own; W. Vaillant, who described the period of inner calm before the establishment of the emotional bond and the development of generativity; D. Levinson, who showed the importance of the connection of dreams with reality, actualization career advancement; G.S. Abramova, who emphasized the need to start a family and achieve intimacy; A.A. Bodalev drew attention to the active reflection of reality and the ability to navigate it and emphasized the significant ties, etc.

The life's journey that determines the development in the period of early adulthood was described by B.G. Ananyev, who showed a coincidence of the phases of the life's journey and age stages of ontogenesis; S.L. Rubinstein, who connected personality formation and the specifics of society and others. Scholars showed the importance of social influence on the development of the personality and noted that it was specific for each age period and was defined by the system of relationships and was reflected in the experiences of the subject by social reality.

Personal enhancement is subject to a certain goal that is presented as an ideal result; with content that determinizes the evolution process. Scientists paid attention to this problem. For example, I.M. Sechenov and N.A. Berstein described the objective determination of the development process; P.K. Anokhin singled out the goal as a result and the systemically important factor of development in a particular period; K.A. Abulkhanova-Slavskaya pointed out that the ability to regulate and organize one's life's journey is subordinate to the purpose and values, as the highest level and quality of the subject of life.

The analysis shows that the period of early adulthood determines the subsequent periods of personality development, creates the basis of its full implementation.

The simulation of the life's journey implies self-determination in current values and goals, it identifies the needs to enable vital choices. As a result, a behavioral strategy is built for the 
implementation of plans in a specific socio-cultural space. The process of self-determination, in the period of early adulthood, connects with complex socio-psychological processes, «it demands" the existence of a solid basis for building a future personality.

According to most scientists, it is morality that creates such a basis. T.V. Suchkova writes about moral requirements, behavior, and will; L.M. Popov, O.Y. Golubeva, P.N. Ustin write about the moral qualities of personality and responsibility, will power; S.V. Agafonov writes about moral choice, strict adherence to moral standards throughout the life`s journey; I.V. Djidarian writes about the preparation of the moralist for the difficulties of implementation, etc.

Russian and Western Scholars such as J. Piaget, D. Watson, L. Kohlberg, L. I. Bozhovich, etc. studied the problem of an individual's moral development, internal and external conditions of the process. Social- medium conditions that determine the development of mechanisms and patterns of moral formation and choices in the period of early adulthood were studied by L.N. Antilogova, N.A. Koval, etc.

Moral (from the noun temper, norvъ) has been historically interpreted as a set of norms that define behavior and society implementation, as well as spiritual and mental qualities, are guided by one's sense of choice of his/her behavior. The standards of morality allow a person to feel like a person; to synchronize his/her interests with the interests of mankind; in communication with others to show his/her personal qualities freely, namely conscience, duty, responsibility, shame, respect, kindness, care, responsiveness, etc.; to rely on basic essential spiritual and moral values.

By the period of early adulthood, a person has gone through the main stages of moral education. Ideally, the process of forming moral qualities, character traits, skills, and habits of behavior has already finished off. By this stage, the desire to overcome inherent defects, the fulfillment of moral standards; a system of motivational values, attitudes, norms of behavior in society, as the core of the moral way of life has formed.

As an integrative characteristic of the individual, morality determines the choice of direction of development in the period of early adulthood, performs the function of synchronization of personal integrity with universal basic values, personal, professional, and social goals, with self-fulfillment. Morality organizes and regulates the intellectual, emotional, and personal spheres to ensure the integrity of the formation of the subject on his life`s journey.

The life`s journey choose depends on mutual assent with moral values. It determines the choice of profession, the start of a family, all subsequent achievements. It is values that determine goals, the pathway of achievement, and therefore future results. Morality is closely related to other processes. It can be concluded that morality is the guaranty of selfdevelopment (K. Rogers, E. Fromm, A. Bruschlinsky), self-actualization and service (W. Frankl), absorption in one's work - (A. Maslow), the ability to love (E. Fromm), maturity (A.A. Derkach), etc.

Moral choice is always a choice based on moral standards that have become an internal compass and guide in the decision-making process. It is a choice of moral behavior that is governed by higher needs and moral motivation. This choice determines self-restraint, selfcontrol, and life stamina. According to A.A. Rean, responsibility, tolerance, selfdevelopment, positive thinking, and attitude to the world determine moral choice; E. Fromm - a responsibility that can be developed inactivity, care, respect, knowledge, S.L. Rubinstein - responsibility, as a person's ability to determinate events; E. Erickson - features of interaction with the environment, due to personal attitude to it.

It is morality that brings self-determination in early adulthood to a new principle level, that requires the use of higher criteria, values that influence the sustainability of self-esteem, self-awareness, " one's self-concept" etc. The moral choice that determines the vector of personal development depends on the environment. In this regard, it is necessary to consider 
the peculiarities and dynamics of moral choice in the period of early adulthood in modern Russian conditions, its transformational processes in recent decades.

\section{Materials and methods}

The theoretical and methodological basis of the research is the principles of determinism, humanism, development, subject, unity of consciousness and activity; A.N. Leontiev's theory of the activities; B.G. Ananyev and S.L. Rubinstein`s the personal approaches; V.P. Sinchenko, A.V. Karpov, B.F. Lomov`s ideas of the systemic approach; L.V. Belyaeva, I.L. Selenkovoy, L.V. Temnova, A.A. Khvostova's researches on moral choice; A.V. Bruschlinsky, K.A. Abulkhanova-Slavskaya's personality studies in the ever-changing society; B.S. Bratus, A.B. Kupreychenko, V.N. Myasishchev`s morality provision based on the interaction of the individual with him/herself and people around; E.A. Klimov, N.S. Pryzhnikov, V.D. Shadrikov's theoretical approaches to the study of the role of morality in the formative period of specialists, etc.

The methods of the research are theoretical analysis and generalization, questionnaires, participant observation, survey, methods of qualitative data analysis, and statistical data manipulation.

The research of the moral choice of an individual in the period of early adulthood was carried out in three stages. The first phase, the analysis of the problem was carried out as part of studies that were conducted in June-July 2007 in Penza, within the framework of a grant of the Russian Humanitarian Science Foundation 07-06-28607a/In 2007-2008, "Transformational processes of the individual spiritual potential as the basis for the successful socialization of the younger generation" [1]. The questionnaire contained questions that studied the moral choice of respondents. A total of 244 students (17-22 years old) were interviewed.

The second study was conducted in January-June 2010 in Penza, as part of the research work "Intergenerational Transformation of the Spiritual and Moral Capacity of a Young Person's Personality in a Modern Sociocultural Environment, as well as the State Regulation of This Process in Ensuring the Sustainable Development of Modern Society in the Conditions of Globalization" within the framework of the Federal Target Program "Scientific and Educational Personnel of Modern Russia 2009-2013." The subjects answered the questionnaire. A total of 110 students (17-22 years old) were interviewed. This made it possible to compare the dynamics of moral choice over three years.

The third phase was in Penza in 2019. The researchers repeated the survey of 2007, 2010 and the sample size was 101 men and women aged 17-22. At the final stage, a comparative analysis of the results of 2007, 2010, and 2019 was carried out, all these allowed to study the dynamics of changing the moral choice of young people. Tables and diagrams were built on questionnaires.

\section{Results}

The generalized analysis of the researches in 2007, 2010, and 2019 in Penza revealed the dynamics of moral choice among students over 12 years. A total of 110 students in 2010, 101 students in 2010, 101 students in 2019, 101 students in 2019 were interviewed.

Questions were clarifying moral choices in the instructions of the questionnaire. Respondents were asked whether they would choose the moral values and ideals that their parents taught them and whether they would follow them in life, despite the transformational processes in the world around them, the difficult socio-economic situation in the country, and the change in the system of values. The questionnaire presented separate questions on the 
ideals, values, goals, and choices of the individual. The generalizing comparative result of the research is presented in Figure 1. The choice of high ideals and the subjects' adherence to them in their lives, in the reality of everyday life, was studied.

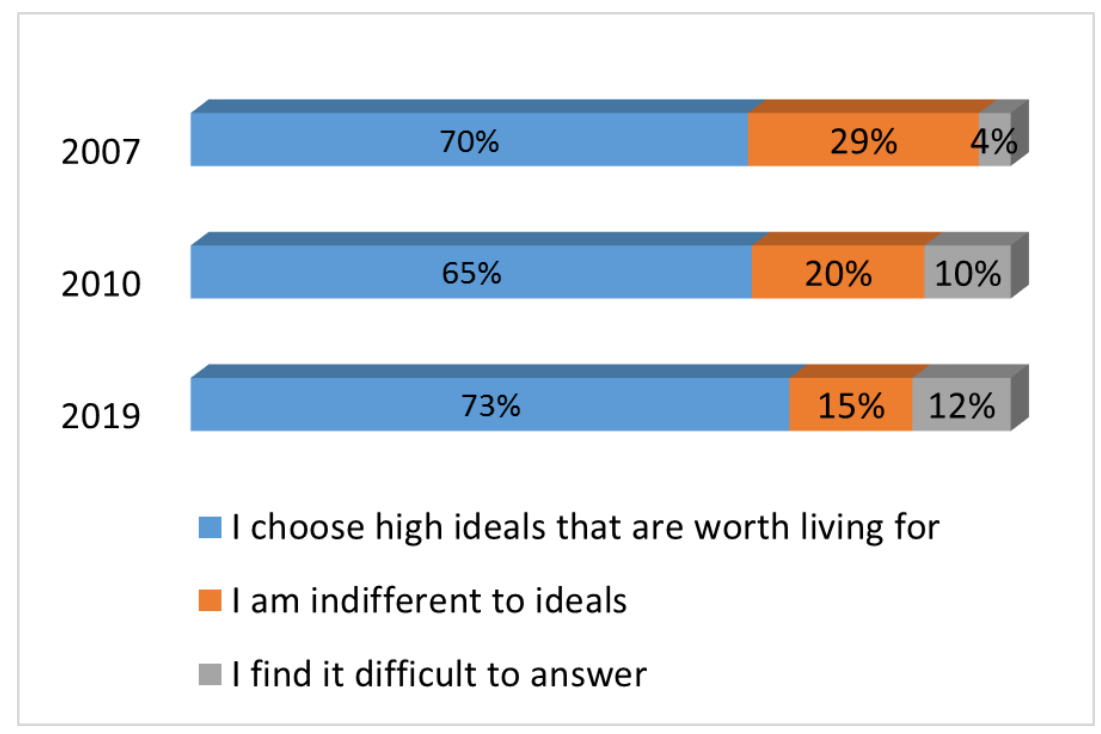

Fig. 1. Youth's attitude to ideals, \%

The results show that the choice of high ideals that are worth living for has not fallen below $65 \%$ among the subjects since 2007 so far. There was a period of declining values, from $70 \%$ in 2007 to $65 \%$ in 2010 , but then it rose again in 2019 to $75 \%$, higher than it was in 2007.

Of particular interest are indicators of indifference to ideals. They decreased from $29 \%$ in 2007 to $20 \%$ in 2010 and $15 \%$ in 2019 , despite the increase in the crisis in society. The decrease in the spread of cynicism and indifference to ideals among young people can be explained as an increase in the crisis in society, as in such periods the personality turns to its psychoprotective, deep, traditional, and essential foundations, and the desire to live meaningfully, which is impossible without reliance on values and ideals of their culture. The data are also confirmed by several studies [2-4].

It is worth paying attention to the fact of an increase in the indicator "difficult to answer", from $4 \%$ in 2007 to $10 \%$ in 2010 and $12 \%$ in 2019 . This shows that the subjects are faced with a choice that is difficult for them. It is the choice that will determine the further path and development of both the individual and the specialist - in the direction of the realization of high ideals and values, service to people or degradation, cynicism, indifference, self-interest and consumption, and therefore destruction.

The result of the activity is always associated with the interests of others, the moral choice that is made in their favor and harmonizes with internal moral beliefs, principles. Conscience and moral attitudes are the benchmarks for such choices. The choice according to them always turns out to be the only right one, which has origins in deeply formed moral traditional beliefs aimed at mutual assistance, friendship, respect, love, etc.

In this regard, research of moral attitude to other people was carried out, namely sacrifice, love for people, generosity, responsiveness, mercy, kindness, compassion. It is the value orientation and help that manifests the moral choice in action (Figure 2). 


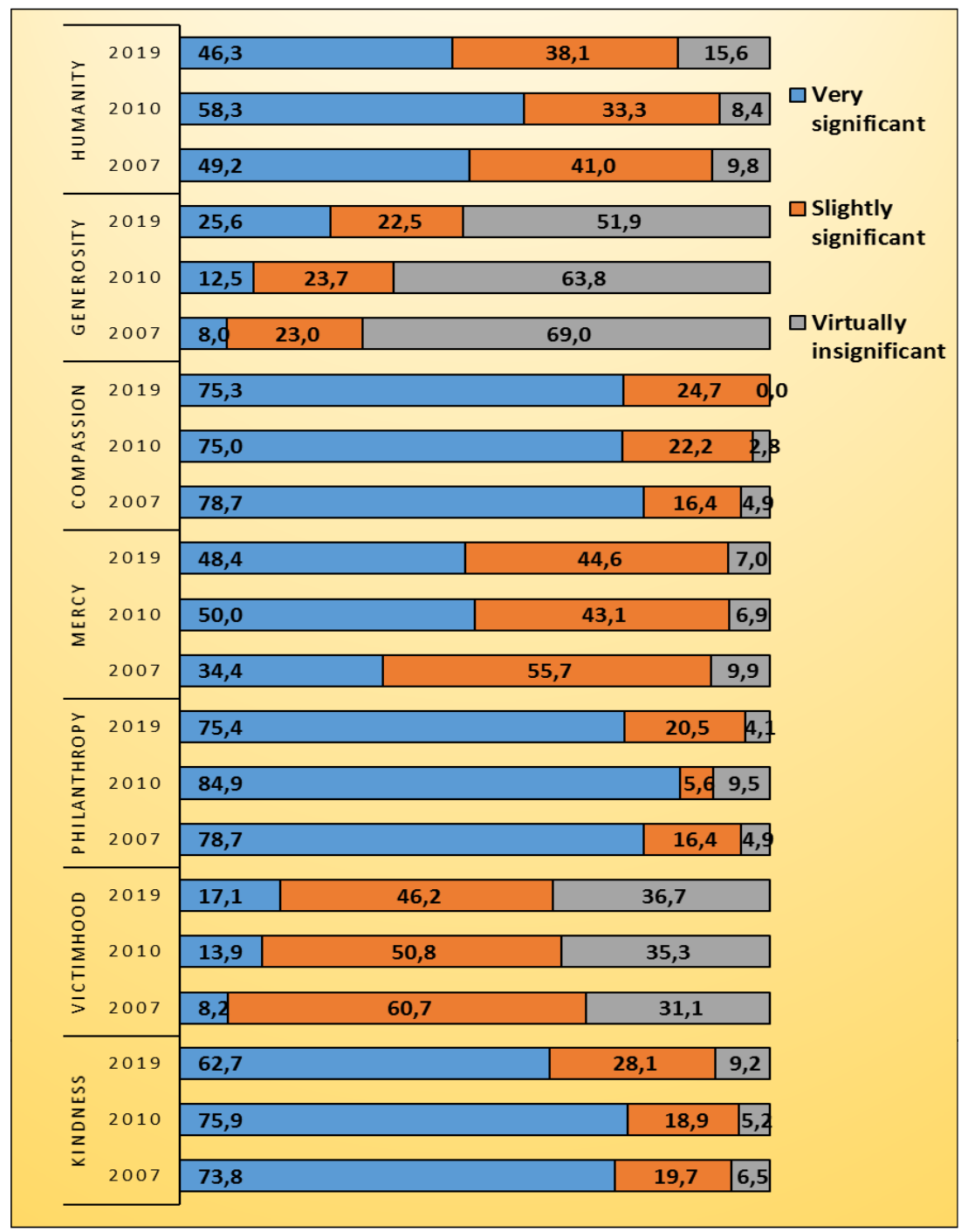

Fig. 2. Choice of moral values to implement in life, in $\%$.

The results of the research indicate that, in general, the indicators of significance, namely, "very significant" and "significant, but not very" give a fairly high percentage of students' choices of moral values, which turn in the process of internalization into internal qualities of personality that determine their actions. The highest scores for responsiveness, combined "very significant" and "significant but not very " gave 100\% in 2019, (75.3\% and $24.7 \%)$ in 2010. $97.2 \%$ (75.0\% and $22.2 \%$ ), in $200795,1 \%$ (78,7\% и 16,4\%). Next in the election hierarchy is love of people. The overall numbers in 2019 are $95.9 \%(75.4 \%$ and $20.5 \%)$, in $201090.5 \%$ (84.9\% and 5.6\%), in $200795,1 \%$ (78,7\% и 16,4\%). Then, it is mercy, in 2019 - $93.0 \%$ (48.4\% and 44.6\%), in 2010 - 93.1\% (50.0\% and 43.1\%), 2007- 90,1\% (34,4\% и $55,7 \%)$. Kindness in 2019 has high rates- $90.8 \%$ (62.7\% and $28.1 \%), 2010-94.8 \%(75.9 \%$ and $18.9 \%), 2007-93,5 \%$ (73,8\% и 19,7\%). Compassion is high $(84.4 \%, 91.6 \%, 90.2 \%)$, sacrifice is average $(63.3 \%, 64.7 \%, 68.9 \%)$, and generosity is low $(48.1 \%, 36.2 \%, 31.0 \%)$. 
If we consider moral values through the indicator "very significant," the choices above $50 \%$ relate to responsiveness, love of people, and kindness, almost $50 \%$ relate to mercy and compassion, and below $25 \%$ relate to generosity and sacrifice.

The main task while ensuring moral choices and decisions to follow conscience is to provide young people with conditions in society that will enable them to build their lives following their inner traditional moral concepts. Self-determination under morality that is realized externally in the moral conditions of society synchronizes the rules of conduct that are accepted in society and the internal rules of the individual. However, self-determination to morality in the changing conditions of modern Russian reality, where space is filled with immoral values and meanings, comes into conflict with the rules of conduct that are accepted in society. During the research of the influence of respect for traditions on the implementation of goals in life, the subjects gave the following results (Table 1).

Table 1. To what extent respect for moral traditions corresponds to the realization of goals in life, in $\%$.

\begin{tabular}{|l|c|c|c|c|}
\hline \multicolumn{1}{|c|}{ Subjects } & $\begin{array}{c}\text { Very } \\
\text { significant }\end{array}$ & $\begin{array}{c}\text { Significant, but } \\
\text { not very }\end{array}$ & $\begin{array}{c}\text { Practically } \\
\text { insignificant }\end{array}$ & $\begin{array}{c}\text { Doesn't make any } \\
\text { difference }\end{array}$ \\
\hline $\begin{array}{l}\text { Students } \\
\text { Year 2007 }\end{array}$ & 18.0 & 54.1 & 24.6 & 3.3 \\
\hline $\begin{array}{l}\text { Students } \\
\text { Year 2010 }\end{array}$ & 33.1 & 41.7 & 15.5 & 9.7 \\
\hline $\begin{array}{l}\text { Students } \\
\text { Year 2019 }\end{array}$ & 25.6 & 56.2 & 15.6 & 2.6 \\
\hline
\end{tabular}

All 2007-2019 test subjects stated not the main importance of moral traditions in modern life, although they noted their necessity in the scale "significant, but not very". A fairly large percentage, from $15.5 \%$ to $24.6 \%$ noted that they are virtually irrelevant and a large percentage, from $2.6 \%$ to $9.7 \%$, noted that it doesn't concern them. The results suggest the contradictions that exist between the inner plan of a person who was brought up on traditional moral principles and the outer plan of implementation in a society where other, immoral values dominate. Thus, in modern conditions of Russian reality, when he/she achieves a goal, every young person of the period of early adulthood will face the problem of moral choice to act following internal moral values or to follow the values of another order.

Table 2. Confidence in the possibility of implementing their life plans, in \%.

\begin{tabular}{|l|c|c|c|c|c|}
\hline \multicolumn{1}{|c|}{ Subjects } & $\begin{array}{c}\text { not entirely } \\
\text { certain }\end{array}$ & $\begin{array}{c}\text { more likely no } \\
\text { than yes }\end{array}$ & Not sure & $\begin{array}{c}\text { more likely } \\
\text { yes than no }\end{array}$ & sure \\
\hline $\begin{array}{l}\text { Students } \\
\text { Year 2007 }\end{array}$ & 2.9 & 3.6 & 7.2 & 59.8 & 25.5 \\
\hline $\begin{array}{l}\text { Students } \\
\text { Year 2010 }\end{array}$ & 3.9 & 4.1 & 12.5 & 48.9 & 30.6 \\
\hline $\begin{array}{l}\text { Students Year } \\
2019\end{array}$ & 7.1 & 9.1 & 5.9 & 64.4 & 13.5 \\
\hline
\end{tabular}

This is also confirmed by the 2007-2019 confidence research in the implementation of life plans. Only a small number of test subjects aged 17-22 answered the question with 
complete confidence. The overwhelming majority only suggested that they could implement their plans «more likely yes than no". By cumulative negative answers ("not entirely certain," " more likely no than yes," "I find it difficult to answer") a rather large percentage $13.7 \%$ in 2007, 20.5 in 2010, and 22.1 in 2019 answered negatively (Table 2).

\section{Discussion}

The implementation of the individual in the socio-cultural space, that expands the boundaries in the actualization of new cultures, societies, and states of the modern world requires the formation of stable reference samples of group consciousness, that depend on traditional education and independent choice of a person's life position, values, standards, living conditions, which he/she follows in different situations.

V. N. Shcherbina [5] in his study of multistructurality shows the formation of multidimensional processes of social interaction in modern society. Each cultural structure has a concrete historical construction of living environment, socio-historical and spatialtemporal certainty. It is stable, it is distinguished by its principles of construction, specific features, it is filled with normative-value constructs that are embodied in the material, spiritual, organizational, and symbolic attributes of life.

Although objectively individuals are in a single process of social life, the author notes that norms and values are understood differently, in different semantic focuses. Individuals in their social activities are guided by the traditional cultural way of life, which has a collective system of value foundations, as an extension and part of their natural being, that contains the structure of the subjective determination of social interactions.

Ventsel Almar [6] in his study also points out the need to follow traditions and norms of behavior following the values of culture. It is especially important to recreate social norms in civil and family rituals in crisis periods of society. At the same time, you should emphasize solidarity, morality, the embedding of moral values in private and public structures.

M.R. Tkachenko's research shows that it is identity as integrity that sets the individual pathway of the life's journey, connects him/her with cultural traditions that prevail spiritual and moral values. "Social identity is revealed through life strategy, which is the practical actions of an individual or group that use all kinds of resources and follow the rules of interactions that adequately respond to a given social context" [7, P. 125]. The author points out that the modern world, penetrating the core of the human personality, restructures identity, and transforms self-determination. As a result, people are involved in an independent search for themselves.

This is also confirmed by the research of N.L. Antonova and A.G. Busygin [8], who show that modern space is turning into a place of refraction of identities. Identity becomes multiple, impermanent. There is a process of construction of new identities, including hybrid ones.

Although E.A. Koval, A.A. Sychev, N.V. Zhadunova [9] state that ideas about the due and the essence are stable and have a significant impact on social reality, they pay attention to the fact that the modern social world is facing a normative revolution and in the course of social development there can be both changes in the value-normative hierarchy within the system of social norms and the appearance of new ones. The authors suggest that ideas about morality, refracted through freedom and reason, form a unique moral "self" of a person in modern society.

If we consider the research of Dadaeva T.M. [10] about the relationship between education, historical memory, and civic identity from the perspective of the basis of moral choice of young people, we pay attention to the fact that there is duality and inconsistency in the perception of historical events of the past among young people. The actualization of the problem occurred because of the modern process of smearing old identities. From the point of view of self-identification, student youth more often feel a sense of community with people 
of common views, their generation, general studies, and profession. Thus, age and professional identity are significantly stronger than ethnicity one.

According to the author, the self-identification of young people is influenced by common significant historical events with deep symbolic meaning, the vast territory of Russia, common problems, common holidays, traditions, the Russian language, love for Russia, history, etc. As factors and phenomena that do not contribute to feelings of pride, the study notes the lack of work, low standard of living, the study of socially and economically deprived region development, the large role of personal ties, poor social protection of the population, etc. The critical attitude was also stated to the socio-political and economic situation in Russia. The significant fact is that $68 \%$ of university students and $53 \%$ of secondary specialized educational institutions students constantly or sometimes felt ashamed of living in Russia. All this does not contribute to the consolidation of identity.

At the same time, only identification with one's own culture gives a person a unique mechanism of self-regulation, social regulation, a powerful psychoprotective mechanism to deal with a particular situation. The situation of any choice is determined by a system of values. The mechanism for the formation of the value basis of identity consists in the internalization (appropriation) of traditional values by the individual in the course of education and self-education.

In the complex world of the cultures formatting, the construction of identities, the transformation of moral values, according to A.S. Alekhnovich, has still preserved human cultural mediation, that is manifested in "the interrelated structures of language (propositional identity), communication (communicative identity), discursive practices (discursive identity), personal and historical memory (narrative identity) and interaction (ethical identity) - all of which correspond to subjective and intersubjective thinking (jointly mediated linguocognitive activity). As a result of these nominative and communicative practices of existing reality, an individual subject is formed with personal identity (predetermined outcome) in the social world. In this organized predetermined outcome, the individual builds up his identity at the level of the individuality of the body, and the personality is at the level of the socially formed selfhood. "[11, P. 50].

The life`s journey simulation implies self-determination in actual values and goals. The process of self-determination, in early adulthood, in connection with complex sociopsychological processes, that construct hybrid and multiple versions of values and identities, still "requires" and the presence of a solid basic foundation for the construction of a person's future.

E.N. Tkach [12], describing the period of studentship, points out the fact that it differs in rethinking one's place in society, re-evaluating the importance of value orientations, and taking responsibility for the results of his activities. All of these are hidden in the motives of the individual and require management. The author's study in 2019 based on the Far Eastern State Transport University (Khabarovsk) of 60 students showed the presence of traditional priorities of the test subjects to bring their work for the benefit of society, to achieve good results and develop mentally, morally, creatively and physically. Students have good emotional involvement (life optimism, emotional composure, and failure tolerance) and the connection between internal socially significant motives and internal individually significant motives. As well as a strong desire to improve their moral character, the development of moral qualities.

Indeed, in the complex specific conditions of social reality, only the essential basis of morality provides safety and stability of the internal normative-value base for the implementation of the personality, its sustainable perspective step-by-step declaring identity. Determined by internal development, personal attitudes, thanks to moral awareness such a person independently controls the course of his/her intellectual and emotional movement to achieve significant results in the behavioral component. 
A.V. Gushchina [13] points out that the emphasizing of moral knowledge allows us to distinguish between good, responsibilities, duty, justice, and guides us to perform moral acts. Without this knowledge, a person is not fully able to express an evaluative and value attitude to facts, phenomena, actions, actions. Values, as a component of morality, act through the motives of moral activity, take the form of an ideal, a guideline of activity that is manifested in the behavioral side of morality - in actions and behavior.

I.G. Savoychinskaya [14] researches the relationship of professionalism and morality, shows the need for a future professional to adopt ethical norms that will determine the values of the orientation of a mature specialist, who aims to achieve the ideal state of performance of his/her official duties, thanks to the moral stability that forms the motives of behavior. The author notes that mental ballast is associated with moral ideals, the ability not to accommodate him/herself to external circumstances, but to change them per the principles of morality. Moral qualities form a person's willingness to take up a position, which is defined by normative documents that contain moral standards. The moral component is a condition for success and it influences the formation of the self-image, which correlates with the image of the profession and the professional and contributes to professional self-awareness.

Studying professional self-consciousness as a factor of personal and professional selfdevelopment of university students, J.G. Garanina and N.V. Andronova [15] point out that the ability to reflect and realize oneself, self-control and self-regulation of behavior creates prerequisites for self-change and self-improvement, lay the groundwork for setting higher professional and life goals, contributes to the process of personal and professional selfdevelopment.

At any stage of implementation, regardless of the formation of moral foundations and qualities of the individual, there may be a situation of moral choice that determines the direction of further development. The choice is often accompanied by hard-to-solve contradictions between the inner world that is filled with the traditional values of life to help someone near and dear to one, and the outside world, which broadcasts other norms of behavior in society - personal gain, self-interest, deception of someone near and dear to one, etc.

The choice always depends on a person. The period of early adulthood provides the first examples of the existence of moral beliefs and values that follow or refuse them. It is at this very moment of choice that the true colors, the degree of development of his/her internal moral qualities, the possibilities, and features of the further realization of life plans are manifested.

In Russia, traditionally in the process of education, morality is formed and it fills the unconscious person from childhood. Choosing a position, making a moral choice in the period of early adulthood, a person shows how synchronous his/her unconsciousness, consciousness, and behavior, how honest he/she is with him/herself and able to help another to forget about his/her interests. The research demonstrated the choice of the test subjects, which consists in deciding to take a moral position, neglect moral internal norms only in a small percentage, and turn immorality into a norm of life.

\section{Conclusions}

It is not always easy to make a moral choice in conditions of moral transformation. In Russian critical situation, during the late 19th century and the first decades of the 20th century, every person faces a choice - to show loyalty to his/her views and principles or to step back from them. It must be acknowledged that modern life has turned for the majority of people, including the Russian youth of the early adulthood period of 17-22 years old, into a struggle for survival. The realities of life quite strongly influence morality, namely the choice of moral ideals and values. The difficulties faced by the young generation often force 
them to put aside a lot of principles. However, it is the impossibility to survive in a crisis without moral reference that drives young people to return to them and choose them. Moral values and principles gain power in a young person`s life decisions and they begin to determine his or her future.

\section{References}

1. D.B. Kazantseva, Transformational Processes of the Spiritual Potential of a Personality (Monograph. Penza: PSU Publishing House. 2010)

2. D.B. Kazantseva, Self-realization of the moral potential of the individual in Russia: monograph. (Prague: Vědecko vydavatelské centrum «Sociosféra-CZ», 2020)

3. D.B. Kazantseva, E.K. Klimova, T.E. Chernisheva, Humanitarian: Actual problems of humanitarian science and education, 20, 2, 174-188 (2020) DOI: 10.15507/20789823.050.020.202002.174-189

4. G.B. Akopov, Cultural-historical psychology. Samara : FGBOU VO SGSPU, 15, 2, 72-78 (2019) DOI: $10.17759 / \mathrm{ch}$ p.2019150208

5. V. N. Shcherbina, Voprosy sotsial'no teoriya, X, 69-79 (2018) DOI: 10.30936/22277951-2018-10-69-79

6. V. Almar, Folklore: structure, typology, semiotics, 2, 3, 70-86 (2019) https://doi.org/10.28995/2658-5294-2019-3-70-86

7. M.R. Tkachenko, Modern research of social problems, 8, 3, 125-139 (2017) DOI: 10.12731/2218-7405-2017-3-125-139

8. N.L. Antonova, A.G. Busygin, Theory and practice of social development, 2 (132), 12 16 (2019) DOI:10.24158/tipor.2019.2.1.

9. E. A. Koval, A.A. Sychev, N.V. Zhadunova, Russian Journal of the Humanities: topical issues of humanitarian science and education, 21, 1, 63-77 (2021) DOI: 10.15507/2078-9823.053.021.202101.063-077

10. T.M. Dadaeva, Russian Journal of the Humanities: topical issues of humanitarian science and education, 20, 1, 41-60 (2020) DOI: 10.15507/20789823.049.020.202001.041-060

11. A.S. Alekhnovich, Issues Social Theory, X, 38-52 (2018) DOI: 10.30936/2227-79512018-10-38-52

12. E. Tkach, O. Perets, E3S Web of Conferences, 210, 1-9 (2020) DOI: https://doi.org/10.1051/e3sconf/202021018132

13. A.V. Guschina, Samara Scientific Bulletin, 8, 3 (28), 270-275 (2019) DOI 10.24411/2309-4370-2019-13306

14. I.G. Zavoychinskaya, Electronic Science Journal, 2 (2014)

15. Zh.G. Garanina, N.V. Andronova, Russian Journal of the Humanities: topical issues of humanitarian science and education, 20, 4, 454-464 (2020) DOI: 10.15507/20789823.052.020.202004.454-464 